\title{
A Clinical Cross Sectional Study of Benign Breast Diseases
}

\author{
Dr. Sapna $\mathrm{T}^{1^{*}}$
}

${ }^{1}$ MBBS, MS, Associate Professor, Department of General Surgery, Sapthagiri Institute of Medical Sciences \& Research Center, 15, Hesarghatta Main Rd, Navy Layout, Chikkasandra, Chikkabanavara, Bengaluru, Karnataka 560090, India

DOI: $\underline{10.36347 / \text { sasjs.2021.v07i02.014 }}$

| Received: 25.01.2021 | Accepted: 12.02.2021 | Published: 19.02.2021

*Corresponding author: Dr. Sapna T

Abstract

Original Research Article

Benign (non-cancerous) breast conditions are unusual growths or other changes involving the breast tissue that cannot be labelled as cancer. Benign breast condition can be confusing and anxiety prone initially as the symptoms routinely masquerade signs and symptoms of breast cancer. There may be a palpable lump or visible discharge from nipple or the mammogram findings may necessitate further testing to arrive at a diagnosis. About 25 cases labelled as breast diseases of benign nature were selected. Detailed history of all the fifty cases was taken according to the proforma. Information regarding age, religion, socio- economic status, nature of symptoms, duration, menstrual status, marital status, breast-feeding were taken. History regarding to the usage of oral contraceptive pills, built and nourishment, habits were also noted. Family history regarding any breast conditions was obtained. A number of breast conditions which are benign in nature usually mimic breast cancer on exam, imaging studies, and in some cases even under the microscope. Sometimes, people are very scary and fearful of missing A BREAST cancer, but even more psychologically dreadfull is the prospect of mistaken thought process that a lump in breast or change in size is cancer when it is not.

Keywords: Benign Breast Diseases, FNAC.

Copyright $\odot 2021$ The Author(s): This is an open-access article distributed under the terms of the Creative Commons Attribution 4.0 International License (CC BY-NC 4.0) which permits unrestricted use, distribution, and reproduction in any medium for non-commercial use provided the original author and source are credited.

\section{INTRODUCTION}

Benign (non-cancerous) breast conditions are unusual growths or other changes involving the breast tissue that cannot be labelled as cancer. Benign breast condition can be confusing and anxiety prone initially as the symptoms routinely masquerade signs and symptoms of breast cancer. There may be a palpable lump or visible discharge from nipple or the mammogram findings may necessitate further testing to arrive at a diagnosis.

Typically benign breast conditions are not cancer; however there are some benign breast conditions that can eventually develop into breast cancer. As per the Experts risk stratification and grouping, benign breast conditions are classified into 3 groups and are as follows.

1. No risk CATEGORY

2. Slight risk CATEGORY

3. Moderate risk CATEGORY

Conditions 1 and 2. Usually and routinely are not investigated further other than the usual breast cancer screening recommendations for women at average risk.

Conditions 3. Carrying a "moderate increase" in breast cancer risk, the treating doctor usually do advice to get more frequent mammography screens and/or other imaging tests in the form of an ultrasound or MRI (magnetic resonance imaging) scan.

\section{Signs and symptoms of benign breast conditions}

Benign breast conditions are of many types which usually because unusual changes in breast tissue. The glandular tissue or the Stromal tissues of the breast may be affected individually or in combination in case of benign breast conditions.

Benign breast conditions typically manifest as an unusual distinct growth or lump that sometimes can be felt through the skin. Also on routine screening, Mammogram also detects and picks up the unusual growth.

- Painful or painless swelling, and/or marked tenderness felt in the breast

- A palpable Lump. 
- Skin irritation

- Redness or scaling on the nipple and/or skin of the breast

- Pain in nipples or retraction (meaning part of the nipple looks like it is puckered or pulling inward)

- Unusual breast discharge other than milk. (The colour may be serous, reddish, greenish, yellow or blackish brown.)

OBJECTIVE: Clinical study of benign breast disease.

\section{METHODOLOGY}

About 25 cases of benign breast diseases were selected during Jan to June 2017. Detailed history of all the fifty cases was taken according to the proforma. Information regarding age, religion, socio- economic status, nature of symptoms, duration, menstrual status, marital status, breast-feeding were taken. The SELECTED patients were systematically examined including breast examination and systematic examination and assessment of nutritional status. All underwent relevant investigations including blood counts- Hb\%, BT, CT, Blood sugar levels (RBS), Renal function tests, Urine examination and EKG. IMAGING tests like USG and Mammography were also done.
RESULTS

Table-1: Age Wise Distribution of Cases

\begin{tabular}{|l|l|l|}
\hline Age in years & No. of patients & \% \\
\hline $21-30$ & 11 & 44 \\
\hline $31-40$ & 09 & 36 \\
\hline $41-50$ & 03 & 12 \\
\hline$>50$ & 02 & 08 \\
\hline Total & 25 & 100 \\
\hline
\end{tabular}

In the current study, 11 cases belong to 21 to 30 year of age category followed by 9 cases belonging to 31-40 years of age category.

Table-2: Distribution of Cases Based on Modes of Presentation

\begin{tabular}{|l|l|c|}
\hline Complaints & No. of patients & \% \\
\hline Lump & 11 & 44 \\
\hline Mastalgia & 07 & 28 \\
\hline Discharge & 03 & 12 \\
\hline Nodularity & 02 & 08 \\
\hline Others (redness retraction) & 02 & 08 \\
\hline
\end{tabular}

In the current study, 11 cases had lump in the breast and 7 cases had mastalgia, discharge present in 3 cases, nodularity in 2 cases.

Table-3: Fine Needle Aspiration Cytology Findings

\begin{tabular}{|l|l|l|}
\hline Fine needle aspiration cytology & No. of patients & \% \\
\hline Fibroadenoma & 12 & 48 \\
\hline Fibrocystic disease & 05 & 20 \\
\hline Antibioma & 02 & 08 \\
\hline Phyllodes & 02 & 08 \\
\hline B/LFA & 1 & 04 \\
\hline Breast abscess & 1 & 04 \\
\hline Keratinou scyst & 1 & 04 \\
\hline Lipoma & 1 & 04 \\
\hline
\end{tabular}

Out of 25 cases, Fibroadenoma comprised of 12 cases, 9 cases fibrocystic disease, Antibioma and phylloides comprised of 2 cases.

\section{DISCUSSION}

In the present study, 11 cases were belongs to 21 to 30 year age group followed by 9 cases belongs to 31-40 year age group, 11 cases presented with lump in the breast and 7 cases presented with mastalgia, discharge was seen in 3 cases, nodularity in 2 cases and 12 cases were Fibroadenoma, 9 cases fibrocystic disease, 2 cases were antibioma and phylloides.

A cross sectional study done by Dr. Uma Krishnaswamy, Apollo Hospitals, Chennai on 1786 Urban Indian Woman who had underwent routine health check-up, revealed that $12.75 \%$ women faced benign breast problems [1].
A prospective study by Tariq Wahab Khanzada et al., at Isra University Hospital, Pakistan highlighted that Fibroadenoma and Fibrocystic disease constituted the most common benign breast diseases seen in $27 \%$ and $21 \%$ of patient's respectively. They also concluded that benign breast conditions are common occurrences in reproductive age group females. The commonest BENIGN condition is Fibroadenoma routinely seen in $2^{\text {nd }}$ and $3^{\text {rd }}$ decades of life. Fibrocystic disease is the next common BBD and the incidence rates increases with advancing age [2].

Dr. Pradhan M, Pathology clinic, Oslo, Norway conducted a study from 2000 to 2004. Fine needle Aspiration cytology was done on 2246 breast lump cases. They concluded that out of 2246 cases, 1840 cases turned out to be non-malignant and amongst 
them, $47 \%$ was fibrocystic, $8 \%$ comprised of fibroadenoma cases, $6 \%$ were abscess [3].

Tewari $M$ et al., Department of Surgical Oncology, Institute of Medical Sciences, Varanasi, conducted a study that highlighted the significance of breast tuberculosis mimicking breast cancer and pyogenic breast abscess. The differentiating diagnosis should be on lines of identification of typical histological features of tuberculosis, cytology and culture [4].

A. K. Al Thobhani et al., Department of Surgery, University of Sana ${ }^{e c}$, Yemen conducted a study on profile of Breast lesion biopsies and showed that $79.9 \%$ of cases were of benign breast conditions and $20.1 \%$ of cases were that of Invasive Carcinomas. Here also, Fibroadenoma presented as the most common lesion $(30 \%)$ with mean age of presentation of 22.2 years, which was followed by fibrocystic disease (27.4\%) and least was breast inflammation (13.1\%) [5].

Engwad et al., conducted a study in 2009 using 783 aspirates to establish the utility of FNAC and CNB in the first preoperative diagnostic tool and conclusively they recommended the utility of FNAC as a primary choice tool in triple diagnostics [6].

A study of benign breast CONDITIONS conducted by SBHGM college Maharashtra in 2011 involving 489 breast lesion cases, revealed that benign breast disease constituted $79 \%$ with fibroadenoma being the most commonest lesion followed by fibrocystic disease of the breast.

A study conducted at a tertiary care hospital in SKIMS, Srinagar (J \& K)(2014) for 3 years, involving women having breast lesions and aged between 15 to 70 years showed that out of 72 cases studied, $77.77 \%$ showed benign nature and $22.22 \%$ turned out to be malignant lesions of breast [7].

\section{CONCLUSION}

The findings of the study highlights the fact that the benign breast diseases and conditions found commonly in many women can masquerade as breast carcinomas sometimes on clinical examination, or radiological imaging studies or even on Histopathology less commonly. Sometimes breast cancers may be missed on many occasions $s$ that may be frightening and upsetting for many people but in reality, a mistaken diagnosis of a lump or a change in breast size, colour or discharge, to that of cancer when it is otherwise ,also packs in emotional volatility in some people. Nevertheless conditions that clinically simulate and mimic breast cancer are not to be neglected and ignored .In such cases, one should resort to additional studies in radiography, core/open biopsies, hematology, tumor markers, so that a definitive diagnosis is arrived at, even if the investigations take an emotional toll on the affected women.

\section{REFERENCES}

1. Krishnaswamy U. Profile of benign breast diseases in urban India. Indian J Surg. 2003 Mar 1;65(2):178-81.

2. Tariq Wahab Khanzada, Abdul Samad, Champa Sushel. Spectrum of Benign breast diseases. Pakistan Journal of Medical Sciences. 2009; 25(2):265-68.

3. Pradhan M, Dhakal HP. Study of Breast Lump of 2246 cases by Fine Needle aspiration. Journal of Nepal Medical education. 2008; 47(172):205-209.

4. Tewari M, Shukla MS. Institute of Medical Sciences Varanasi, India. Breast Tuberculosis. Diagnosis Clinical features and management. Indian J Med. 2005; 122(2):103-10.

5. Al-Thobhani AK, Raja YA, Al-Romaimah MA. Profile of Breast Lesions among women with positive biopsy findings in Yemen. Eastern Mediterranean Health Journal. 2006; 12(5).

6. Sadler TW. Langman ${ }^{\text {ee }}$ Medical Embryology, (ed 11) Baltimore, MD: Lippincott Williams \& Wilkins, 2009.

7. Pfeifer JD, Barr RJ, Wick MR. Ectopic breast tissue and breast-like sweat gland metaplasias: an overlapping spectrum of lesions. J CutanPathol. 1999; 26:190-196. 